\title{
FATTY ACIDS COMPOSITION OF TOCTE (JUGLANS NEOTROPICA DIELS) WALNUT FROM ECUADOR
}

\begin{abstract}
VILCACUNDO E ${ }^{1}$, ALVAREZ $\mathrm{M}^{2}$, SILVA M², CARPIO C ${ }^{2}$, MORALES $\mathrm{D}^{2}$, CARRILLO $\mathrm{W}^{1,2 *}$
${ }^{1}$ Department of Research. Bolivar State University, Academic Campus Alpacha. Av Ernesto Che Guevara s/n and Av Gabriel Secaira, EC 020150, Guaranda, Ecuador. ${ }^{2}$ Laboratory of Functional Foods, Faculty of Foods Science and Engineering, Technical University of Ambato. Av Los Chasquis y Rio Payamino. Campus Huachi, CP 1801334, Ambato Ecuador. Email: wi.carrillo@uta.edu.ec
\end{abstract}

Received: 26 November 2016, Revised and Accepted: 03 May 2017

ABSTRACT

Objective: The aim of this study was to determine the fatty acids composition in a tocte seeds oil (Juglans neotropica Diels) sample cultivated in Ecuador.

Methods: Tocte oil was obtained from tocte seeds using the cold pressing method. Fatty acids analysis was carried out using the gas chromatography method with a mass selective detector (GC/MSD) and using the database Library NIST14.L to identify the compounds.

Results: Methyl esters fatty acids were identified from tocte (J. neotropica Diels) walnut using the GC-MS analytical method. The total lipid content of tocte walnuts seeds of plants cultivated in Ecuador was of $49.01 \%$ of the total lipid content on fresh weight. Fatty acids were analyzed as methyl esters on a capillary column DB-WAX 122-7062 with a good separation of palmitic acid, stearic acid, oleic acid, linoleic acid, and linolenic acid. The structure of methyl esters fatty acids was determined using the GC-MS. Tocte walnut presents 5.05\% of palmitic acid, $2.26 \%$ of stearic acid, $19.50 \%$ of oleic acid, $65.81 \%$ of linoleic acid, and $2.79 \%$ linolenic acid of the total content of fatty acids in tocte oil. Fatty acids content reported in this study were similar to the data reported for other walnuts seeds.

Conclusions: Tocte seeds are a good source of monounsaturated and polyunsaturated fatty acids. Tocte oil content oleic acid and with a good content of $₫ 6 \alpha$-linoleic and $₫ 3 \alpha$-linolenic. Tocte walnut can help reduce risk cardiovascular diseases in Ecuador for their good composition of fatty acids.

Keywords: Walnuts, Tocte, Juglans neotropica Diels, Fatty acids, Lipids.

(C) 2018 The Authors. Published by Innovare Academic Sciences Pvt Ltd. This is an open access article under the CC BY license (http://creativecommons. org/licenses/by/4. 0/) DOI: http://dx.doi.org/10.22159/ajpcr.2018.v11i2.16344

\section{INTRODUCTION}

Genus Juglans also known as walnut has about 23 species distributed in North, Central and South America, Eastern Europe, and Asia. The two most important species from the economic point of view are the Persian walnut (Juglans regia) appreciated for the quality of its nuts and the black walnut (Juglans nigra) highly prized for the quality of its timber. In South America, there are the following species: Argentinian walnut (Juglans australis), Bolivian walnut (Juglans boliviana), and black cedar (Juglans neotropica) found in Colombia, Venezuela, Peru, and Ecuador and known as tocte [1,2].

China has a high production of walnut (J. regia) with 1655 tons in 2011, thus being the most dispersed walnut tree in the world $[3,4]$. Walnuts have a high nutritional value due to their high composition of oils (65\%) and proteins (18-24\%). They are used in the manufacturing of chocolates, and as ingredients in the production of many food and bakery products [5,6]. Composition of oils has been widely studied in other walnut species. However, there are no studies of oil composition in the J. neotropica Diels.

The food habits play an important role in the factors related with a good health. Consumption of junk food has increased considerably, leading to a number of diseases related to important nutritional deficiencies and excess of trans fat $[7,8]$. At present, consumers are more interested in knowing the potential nutritional benefits, disease control or prevention of certain foods, and including healthy food as walnuts in their diets [9]. Foods and their derivate are known to play an important role in reducing health risks and improving health quality. In 2003, the Food and Drug Administration of USA has approved health claims indicating that diets rich in walnuts can reduce the risk of heart disease [10]. Nuts have become an indispensable component of healthy diets and are included in the American Heart Association dietary metrics for defining ideal cardiovascular health in their recent report on setting goals for health promotion and disease reduction for 2020 [11]. The aim of this work was to identify the fatty acids composition present in tocte (J. neotropica Diels) walnut from Ecuador using the gas chromatography-mass spectrometer (GC-MS).

\section{METHODS}

\section{Total lipid extraction}

Tocte walnuts were obtained in the supermarket of Ecuador. Tocte oil sample was obtained from tocte walnuts using the cold pressed method. Oil was then stored at $4.0 \pm 2{ }^{\circ} \mathrm{C}$. Oil extraction was conducted using a Soxhlet apparatus for approximately $5 \mathrm{~h}$ with hexane as solvent, with a solid-to-solvent ratio of $1 / 7 \mathrm{~m} / \mathrm{v}$. After the extraction process, the flask contents were filtered, and the liquid fraction containing the lipid extract and solvent was poured into a 250 -mL flask of a rotary film evaporator to remove the solvent. The obtained oil was collected, evaporated under nitrogen, weighed, and stored in sealed amber glass vials at $-20^{\circ} \mathrm{C}$ until analysis [12].

\section{Methyl esters fatty acids (FAME)}

FAME were prepared from 3 to $5 \mathrm{mg}$ of total lipids using the two-step methylation method $\left(1 \% \mathrm{NaOCH}_{3} / \mathrm{MeOH}\right.$ followed by $\left.5 \% \mathrm{HCl} / \mathrm{MeOH}\right)$; both steps were performed at $60^{\circ} \mathrm{C}, 20 \mathrm{~min}$ FAME were extracted with $6 \mathrm{ml}$ of hexane [13].

\section{Analysis of FAME from tocte by GC-MS}

The fatty acid composition of oil extracted from tocte walnut seeds was analyzed by injecting fatty acid methyl esters [14] into an Agilent Technologies 7980A system GC (Agilent, Santa Clara, CA) equipped with a mass selective detector 5977A GC/MSD, an auto-sampler 7693, column $(60 \mathrm{~m} \times 250 \mu \mathrm{m} \times 0.25 \mu \mathrm{m}$, DB-WAX Agilent 122-7062). The oven temperature was programmed as follows: From $80^{\circ} \mathrm{C}$; ramp 1: To 
$100^{\circ} \mathrm{C}$ at $20^{\circ} \mathrm{C} /$ min during $1 \mathrm{~min}$; ramp 2 : At $200^{\circ} \mathrm{C}$ at $25^{\circ} \mathrm{C} / \mathrm{min}$ during $10 \mathrm{~min}$; and ramp 3: At $250^{\circ} \mathrm{C}$ at $2^{\circ} \mathrm{C} / \mathrm{min}$. The injector and detector temperatures were set at $250^{\circ} \mathrm{C}$. Helium was used as carrier gas at a linear flow velocity of $1.4 \mathrm{~mL} / \mathrm{min}$.

Spectra were compared with the NIST14.L library and the fatty acids mass spectra archive [15]. All GC analyses of the fatty acids were carried out in triplicate, and the results were expressed as the mean value \pm standard deviation

\section{RESULTS}

The GC chromatogram of methyl esters fatty acids from tocte oil present five majoritarian peaks that were separated with a column Agilent DB-WAX 122-7062. These peaks were identified with the help of a spectrum of database NILTS14.L. The quantification of fatty acids was obtained using the peak area ratio. Fig. 1 shows five majoritarian peaks with a good separation and definition, these peaks were identified C16:0 with a retention time of $19.378 \mathrm{~min}, \mathrm{C} 18: 0$ with a retention time of $26.057 \mathrm{~min}, \mathrm{C} 18: 1$ with a retention time of $26.919 \mathrm{~min}, \mathrm{C} 18: 2$ with a retention time of $28.693 \mathrm{~min}$, and finally C18:3 with a retention time of $31.092 \mathrm{~min}$.

The concentration of FAME was measured using the peak area ratio. Table 1 summarizes C16:0: With $5.05 \% \pm 0.90$ of fatty acid total content, C18: With $2.26 \% \pm 0.16$ of fatty acid total content, C18:1 with $19.50 \% \pm 0.44$ of fatty acid total content, C18:2 with $65.81 \% \pm 1.14$ of fatty acid total content, and C18:3 with $2.79 \% \pm 0.26$ of fatty acid total content of tocte oil. Total lipid of tocte walnut seeds was of $49.01 \%$ of lipid in fresh weight (Table 1).

The mass spectrum of methyl esters fatty acids obtained from tocte oil is shown in Fig. 2. The identity and structures of these fatty acids were confirmed by the GC-MS method. Palmitic acid (C16:0) was identified using the mass spectrum with ions of mass/charge $(\mathrm{m} / \mathrm{z})$ between 57 and $270 \mathrm{~m} / \mathrm{z}$. In the previous range, the ions 74 and $87 \mathrm{~m} / \mathrm{z}$ were the most abundant in the mass spectrum (Fig. 2a).

Stearic acid (C18:0) was identified using the mass spectrum with ions with $\mathrm{m} / \mathrm{z}$ between $55-298 \mathrm{~m} / \mathrm{z}$. In the previous range, the ions 74 and $87 \mathrm{~m} / \mathrm{z}$ were the most abundant in the mass spectrum (Fig. 2b).

Oleic acid (C18:1) was identified using the mass spectrum with ions $\mathrm{m} / \mathrm{z}$ between 55 and $296 \mathrm{~m} / \mathrm{z}$. In the previous range, the two ions with the highest abundance were the $55-69 \mathrm{~m} / \mathrm{Z}$.

Linoleic acid (C18:2) was identified using the mass spectrum with ions $\mathrm{m} / \mathrm{z}$ between 55 and $294 \mathrm{~m} / \mathrm{z}$. In the previous range, the two most present ions were the 55 and $67 \mathrm{~m} / \mathrm{z}$.

When the tocte walnut fatty acid composition is compared to some common vegetable oils, it can be seen that olive oil has a high content of monounsaturated fatty acids, C18:1 named oleic acid with $77.6 \%$ of oleic acid. It can be seen that tocte oil from Ecuador has a good content of monounsaturated fatty acids with a content of $19.50 \%$ of oleic acid. Tocte oil has also a high content of polyunsaturated fatty acids with $65.81 \%$ of linoleic acid. Olive oil contains few omega- 6 and omega- 3 fatty acids with $9.0 \%$ and $1.0 \%$, respectively, and macadamia oil contains $3.22 \%$ of omega 6 and $1.79 \%$ of omega 3 (Table 2).

\section{DISCUSSION}

Manos et al., 2001 [22] reported fatty acids content of J. neotropica Diels with $5.0 \%$ of palmitic acid, $3.0 \%$ of stearic acid, $39 \%$ of oleic acid, $50 \%$

Table 1: Total lipid and fatty acids composition of tocte oil sample from Ecuador by GC/MS analysis and their percentage

\begin{tabular}{llll}
\hline $\begin{array}{l}\text { Retention } \\
\text { time (min) }\end{array}$ & $\begin{array}{l}\text { Peak area } \\
\text { ratio \% }\end{array}$ & $\begin{array}{l}\text { Carbon number: } \\
\text { Double bound }\end{array}$ & FAMEs name \\
\hline 19.378 & $5.05 \pm 0.09$ & C16:0 & Palmitic acid \\
26.057 & $2.26 \pm 0.16$ & C18:0 & Stearic acid \\
26.919 & $19.50 \pm 0.44$ & A9 C18:1 & Oleic acid \\
28.693 & $65.81 \pm 1.14$ & A9, 12 C18:2 & Linoleic acid \\
31.092 & $2.79 \pm 0.25$ & A9, 12 C18:3 & Linolenic acid \\
Total lipid \% & $49.01 \pm 0.5$ & & \\
fresh weight & & & \\
\hline
\end{tabular}

FAMEs: Methyl esters fatty acids, GC-MS: Gas chromatography-mass selective

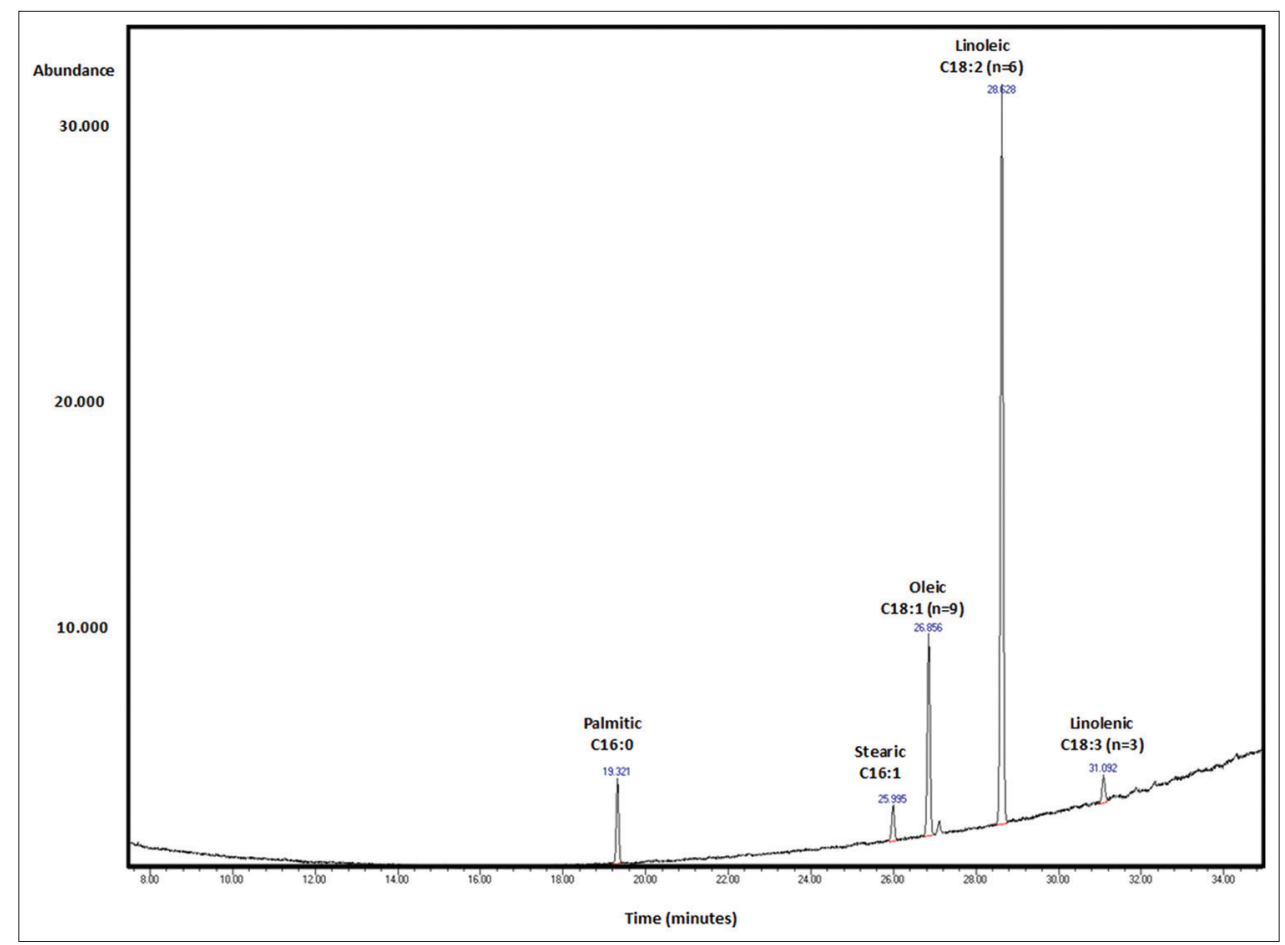

Fig. 1: Analysis by gas chromatography of methyl esters fatty acid from tocte oil 


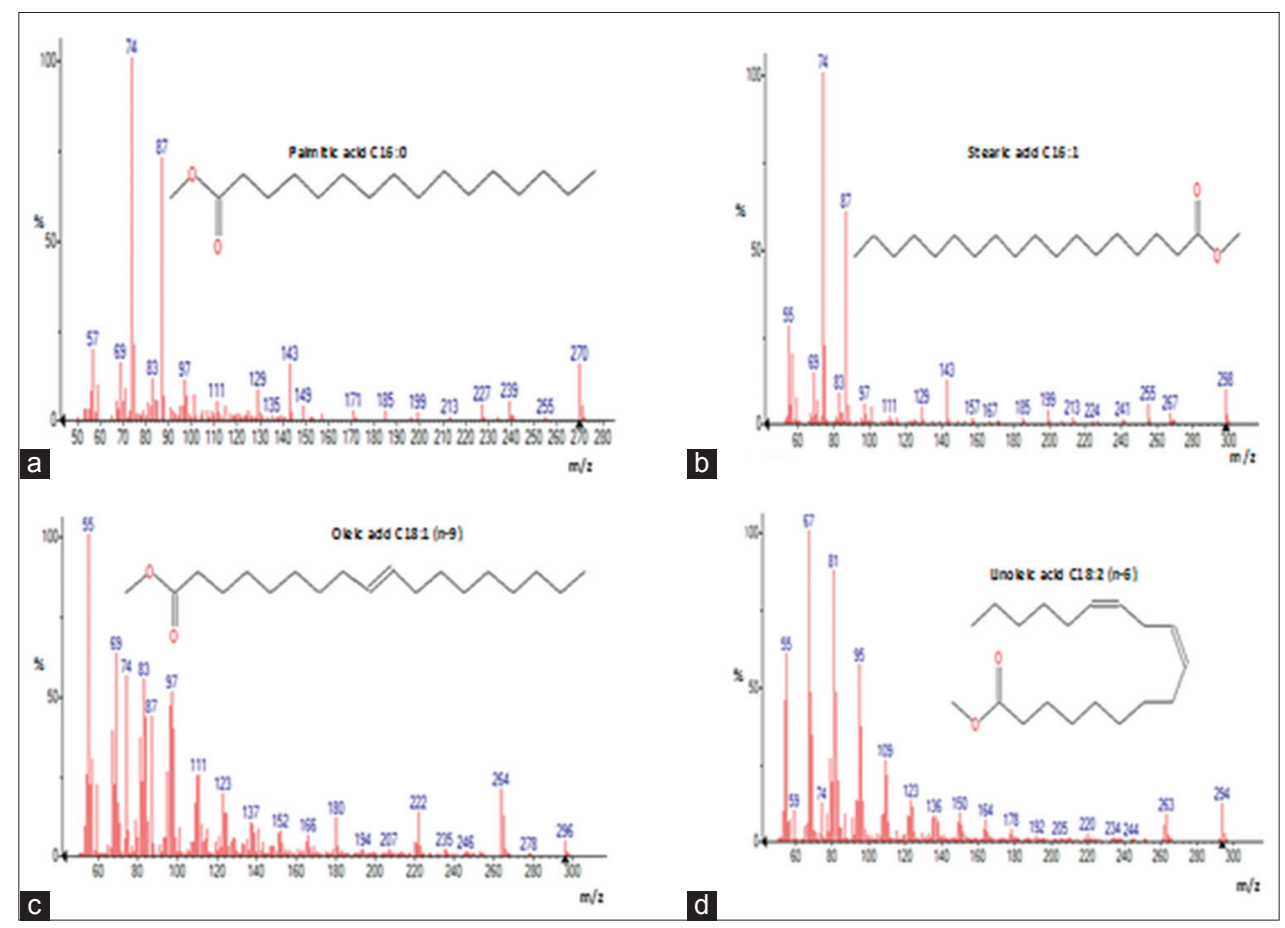

Fig. 2: (a-d) Mass spectrum of methyl esters fatty acids from tocte oil

Table 2: Fatty acid composition (\%) of 10 vegetable oils

\begin{tabular}{|c|c|c|c|c|c|c|c|}
\hline References & Vegetal oil & C16:0 & C16:1 & C18:0 & C18:1 & C18:2 & C18:3 \\
\hline [16] & Olive oil & 13.8 & 1.4 & 2.8 & 71.6 & 9.00 & 1.0 \\
\hline [16] & Sunflower oil & 5.2 & 0.1 & 3.7 & 33.7 & 56.5 & 0.0 \\
\hline [16] & Palm oil & 44.8 & 0.0 & 4.6 & 38.9 & 9.5 & 0.4 \\
\hline [16] & Soybean oil & 10.1 & 0.0 & 4.3 & 22.3 & 53.7 & 8.1 \\
\hline [16] & Corn oil & 11.6 & 0.0 & 2.5 & 38.7 & 44.7 & 1.4 \\
\hline [17] & Sacha inchi oil & 3.98 & 0.0 & 3.12 & 8.58 & 34.98 & 47.04 \\
\hline [18] & Sambo oil & 9.33 & 0.0 & 6.84 & 41.36 & 33.98 & 0.0 \\
\hline [20] & Kahai oil & 19.32 & 0.0 & 3.47 & 18.59 & 68.04 & 0.0 \\
\hline \multirow[t]{2}{*}{ [21] } & Walnut Juglans regia & 7.80 & N.D & 2.30 & 23.10 & 66.54 & N.D \\
\hline & Tocte oil & 5.05 & 0.0 & 2.26 & 19.50 & 65.81 & 2.79 \\
\hline
\end{tabular}

of linoleic acid, and 3\% of linolenic acid. We reported 19.50\% of oleic acid and $65.81 \%$ of linoleic acid these differences can be due at system crop, quality soil, and other factors.

J. regia is the most cultivated walnut around the world with different varieties. Iqbal et al., 2016 [21] have reported fatty acids contents in two varieties (Softshell and Hardshell) from J. regia cultivated in Pakistan with $7.80 \%$ and $7.21 \%$ of palmitic acid, respectively, $2.30 \%$ and $2.20 \%$ of stearic acid, respectively, $23.10 \%$ and $23.15 \%$ of oleic acid, respectively, and $66.54 \%$ and $66.60 \%$ of linoleic acid, respectively. Pereira et al., 2008 [10] have reported the fatty acids composition of six varieties of walnut (J. regia) cultivated in Portugal. Variety Franquette with a value of $6.61 \%$ palmitic acid, $3.07 \%$ of stearic acid, $20.22 \%$ of oleic acid, and $55.51 \%$ linoleic acid. Variety Lara with a value of $6.28 \%$ of palmitic acid, $2.80 \%$ of stearic acid, $14.92 \%$ of oleic acid, and $60.30 \%$ of linoleic acid. Variety Marbot with a value of $6.35 \%$ of palmitic acid, $2.78 \%$ of stearic acid, $16.34 \%$ of oleic acid, and $59.66 \%$ of linoleic acid. Variety Mayette with a value of $5.95 \%$ of palmitic acid, $2.70 \%$ of stearic acid, $16.08 \%$ of oleic acid, and $57.14 \%$ of linoleic acid. Variety Mellanaise with a value of $6.31 \%$ of palmitic acid, $2.80 \%$ of stearic acid, $17.09 \%$ of oleic acid, and $58.75 \%$ of linoleic acid. Variety Parisienne with a value of $6.16 \%$ of palmitic acid, $2.90 \%$ of stearic acid, $19.50 \%$ of oleic acid, and $57.68 \%$ of linoleic acid. Data obtained on this study from walnut (J. neotropica Diels) are therefore in accordance with the content of fatty acids reported in walnut (J. regia) in previous studies. In conclusion, tocte oil has a high content of oleic acid with $19.50 \%$ and linoleic acid with $65.81 \%$. Tocte walnuts have a similar profile of fatty acids reported as the ones reported for the traditional walnut $J$. regia variety. Walnuts constituents have been actively used in nutrition in slowing cancer growth by its antiproliferative and antiangiogenic mechanisms [23]. We also know that linolenic acid has different biological activities as anti-inflammatory, antioxidant, and hypolipidemic activities [24].

\section{CONCLUSION}

Tocte walnut seeds possess a good proportion of monounsaturated and polyunsaturated acids. The content of oleic acid presents in tocte walnut seeds was high. J. neotropica Diels can be used to reduce the risk of cardiovascular diseases. Tocte oil can also be used as a good source of fatty acids with possible biological activities.

\section{ACKNOWLEDGMENTS}

This study was supported by Universidad Técnica de Ambato, Ecuador (Project CPU-1373-2014-UTA) and Project Canje de Deuda EspañaEcuador. This work has been reviewed in the English edition by Emilio Labrador. 


\section{AUTHOR CONTRIBUTIONS}

Vilcacundo E, Carpio C, Morales D, and Carrillo W conceived and designed the experiments. Silva M and Alvarez M performed the gas chromatography analyses. Carrillo $\mathrm{W}$ wrote the paper.

\section{CONFLICT OF INTERESTS}

The authors declare no conflict of interest.

\section{REFERENCES}

1. Mao X, Hua Y. Composition, structure and functional properties of protein concentrates and isolates produced from walnut (Juglans regia $\mathrm{L}$.). Int J Mol Sci 2012;13:1561-81.

2. FDA. Qualified Health Claims: Letter of Enforcement DiscretionWalnuts and Coronary Heart Disease. Washington, DC: FDA; 2014.

3. Mao X, Hua Y, Chen G. Chemical composition, molecular weight distribution, secondary structure and effect of $\mathrm{NaCl}$ on functional properties of walnut (Juglans regia $\mathrm{L}$ ) protein isolates and concentrates. J Food Sci Technol 2014a;51:1473-82.

4. Mao X, Hua Y, Chen G. Amino acid composition, molecular weight distribution and gel electrophoresis of walnut (Juglans regia L.) proteins and protein fractionations. Int J Mol Sci 2014;15:2003-14.

5. Ospina C,HernándezR,AristizabalF,PatiñoJ, SalazarJ.Elcedronegro: Una especie promisora de la zona cafetera. Cenicafé 2003;25:1-40.

6. Amaral JS, Casal S, Pereira JA, Seabra RM, Oliveira BP. Determination of sterol and fatty acid compositions, oxidative stability, and nutritional value of six walnuts (Juglans regia L.) cultivars grown in Portugal. J Agric Food Chem 2003;51:7698-702.

7. Manisha P, Rohit KV, Shubhini AS. Nutraceuticals: New era of medicine and health. Asian J Pharm Clin Res 2010;3:11-5.

8. Pang G, Xie J, Chen Q, Hu Z. How functional foods play critical roles in human health. Food Sci Hum Wellness 2012;1:26-60

9. Hardy G. Nutraceuticals and functional foods: Introduction and meaning. Nutrition 2000;16:688-9.

10. Pereira JA, Oliveira I, Sousa A, Ferreira IC, Bento A, Estevinho L. Bioactive properties and chemical composition of six walnuts (Juglans regia L.) cultivars. Food Chem Toxicol 2008:46:2103-11.

11. Lloyd-Jones DM, Hong Y, Labarthe D, Mozaffarian D, Appel LJ, Van Horn L, et al. Defining and setting national goals for cardiovascular health promotion and disease reduction: The american heart association's strategic impact goal through 2020 and beyond. Circulation 2010;121:586-613.

12. Kamal-Eldin A, Andersson R. A multivariate study of the correlation between tocopherol content and fatty acid composition in vegetable oils. J Am Oil Chem Soc 1997;4:375-80.

13. Gutiérrez LF, Rosada LM, Jiménez A. Chemical composition of Sacha Inchi (Plukenetia volubilis L.) seeds and characteristics of their lipid fraction. Grasas Aceites 2011;62:76-83

14. House SD, Larson PA, Johnson RR, DeVries JW, Martin DL. Gas chromatographic determination of total fat extracted from food samples using hydrolysis in the presence of antioxidant. J Ass Off Anal Chem 1994;77:960-5.

15. Christie WW. Mass Spectrometry of Fatty acid Derivatives; 2014. Available from: http://www.lipidlibrary.aocs.org/ms/masspec.html. [Last accessed on $2014 \mathrm{Mar}$.

16. Iqbal M, Bhatti IA, Shahid M, Nisar J. Physicochemical characterization, microbial decontamination and shelf life analysis of walnut (Juglans regia $\mathrm{L}$ ) oil extracted from gamma radiation treated seeds. Bioc Agric Biotechnol 2016;6:116-22.

17. Dyer JM, Stymne S, Green AG, Carlsson AS. High valueoils in plants. Plant J 2008;54:640-55.

18. Carrillo W, Quinteros MF, Carpio C, Morales D, Vasquez G, Alvarez M, et al. Identification of fatty acids in sacha inchi oil (Pluketenia Volubilis L.) from Ecuador. Asian J Pharm Clin Res 2017.

19. Carrillo W, Carrillo C, Carpio C, Morales D, Vilcacundo E, Alvarez M, et al. Characterization of fatty acids in sambo oil (Cucurbita ficifolia L.) from Ecuador. Asian J Pharm Clin Res 2017;

20. Carrillo W, Carpio C, Morales D, Vilcacundo E, Alvarez M. Fatty acids composition in macadamia seeds oil (Macadamia integrifolia) from Ecuador. Asian J Pharm Clin Res 2017;10:303-6.

21. Carrillo W, Greffa J, Carpio C, Morales D, Vinueza D, Alvarez M. Determination of fatty acids in Kahai oil (Caryodendron orinocense) from Ecuador. Asian J Pharm Clin Res 2017;

22. Paul SM, Stone DE. Evolution, phylogeny, and systematics of the juglandaceae. Ann Mo Bot Gard 2001;8:231-69.

23. Perugu S, Vemula R, Rao MV. Walnut pedunculagin a probable serm for breast cancer treatment. Int J Pharm Pharm Sci 2011;7:233-5.

24. Ramzi GA, Puneeth HR, Madhu CS, Sharada AC. Antagonistic effects of combination of flaxseed oil and Spirulina platensis oil on their biological properties. Int J Pharm Pharm Sci 2015;7:122-7. 